\title{
Comparison on the Development Status of Golf in China and South Korea With the Development Plan of Golf Popularization in China
}

\author{
Xiaohui Yuan ${ }^{1, *}$ Shaohui $\mathrm{Hu}^{1}$ Bingcan $\mathrm{Li}^{1}$ Pengpeng Tang ${ }^{1}$ \\ ${ }^{1}$ College of Physical Education, Sichuan Agricultural University, Ya'an, Sichuan 625014, China \\ "Corresponding author.
}

\begin{abstract}
On October 9, 2009, the International Olympic Committee (IOC) held a plenary session in Copenhagen and decided to officially include golf in the 2016 and 2020 Olympic Games. Golf is back on the Olympic scene. With the approval of General Administration of Sport of China, it was officially included in the 12th National Games of the People's Republic of China in 2013 and has two projects for men and women groups. While attaching importance to golf, China should aim to build a healthy China and a strong sports country, serve the goal of building a moderately prosperous society in all respects and meet the needs of the people for sports, rather than make the sport exclusive to the rich. [1] By comparing with South Korea, one of the Asian countries where golf is most popular, this paper finds out the strategies suitable for popularizing golf in China.
\end{abstract}

Keywords: golf, comparison, popularization, countermeasures

\section{INTRODUCTION}

In 2017, China's sports reform entered a fast track. In addition to football and basketball, 10 Olympic sports, including golf, were also used as the breakthrough point of individual sports reform. In early 2019, the clean-up of golf courses ended, with 187 courses disappearing and 496 being allowed to continue operating. This rectification storm will promote the orderly and healthy development of golf courses in China. Golf in China has entered a new normal development stage. On the one hand, encouraging and supporting the development of cultural and sports industry has become a national strategy. The development of golf has entered into the agreed process of the 13th five-year plan, and the prospect of golf as an international mainstream sport and a special sport encouraged by the state is promising. [5] On October 9, 2009, the International Olympic Committee (IOC) held a plenary session in Copenhagen and decided to officially list golf in the 2016 and 2020 Olympic Games. After golf returned to the Olympic stage, it was officially included in the 12th National Games of the People's Republic of China of 2013 with the approval of General Administration of Sport of China. Team events for men and women were set up. [1] In 2016, Feng Shanshan won a bronze medal at the Rio Olympic Games. Lin Xiyu, a 20-year-old from Guangzhou, hit the first a hole in one on the 140-yard 8th hole of the third round of the Olympic women's golf tournament, the first in the 116-year history of the event. The
Chinese team did well in the Olympic women's golf event. [7] However, China lags behind Japan and South Korea in the development and popularity of golf in Asia, let alone the whole world. Golf in South Korea, in particular, is growing rapidly. In the forum of the 8th China-Foreign Media Golf Forum and Golf Media Competition, the Korean journalists mentioned that in the 1990s, the population of golf players in South Korea was only 1 million and there were 200 golf courses, but now there are 2 million and nearly 500 golf courses. South Korea's indoor golf system has reached 2,500, and golf has become the "national sport" of South Korea. [3] By comparing with South Korea, this paper finds out the strategies suitable for popularizing golf in China.

\section{GOLF IN SOUTH KOREA}

\section{A. Development of golf in South Korea}

The development of golf in South Korea has a history of more than 100 years. The first golf course in 1897 was a six-hole golf course on the coast of Wonsan city, and the Americans established the capital golf club in Hyochang Park. In 1929, the esquire golf course was established and the public began to understand golf. In 1941, Korean player Yeon Dechun won the Japanese golf championship, which made more people know about golf. World War II led to the closure of golf courses. In 1954, after the war, Golf courses on an international scale were being built. After the 5.16 
military event, golf has seen a huge growth. In 1956, Yeon Dechun and Park Mingchu played in the World Cup in London, England, their first international match. In 1960, the golf course was expanded and it became popular. In 1970, the number of people starting to play golf has grown exponentially. In 1978, the first women's golf tournament was held. After the 1980s, various golf courses have increased. In 1988, Ok-Hee $\mathrm{Ku}$ became the first South Korean player to qualify for the LPGA. In 1998, Pak Se Ri won two grand slams and inspired the development of women's golf. In 1999, the number of domestic golf events in South Korea has tripled to 15 for women. As Pak Se Ri, Mi Hyun Kim, Grace Park, and Hee-Won Han have been in the United States on the stage to win, and become a national star, the domestic golf has obtained a great leap forward. In 2002, Choi Kyung-ju's ninth place finish at the tour championships made him a star on the PGA Tour that year. He is the first South Korean and only the fourth Asian player to win the PGA Tour. He won the Compaq Classic of New Orleans and Tampa Bay Championship, earning \$2.2 million that year and ranking 17th. At the World Cup in Mexico, Choi Kyung-ju also paired with compatriot Hui seok-ho to finish third, giving the South Korean men's golf a leap forward. [1] Both men and women won international championships, giving a big boost to the development of professional golf in South Korea. In 2003, there are 11 men's and 13 women's golf tournaments in South
Korea. Inbee Park, 28, was the only South Korean player to win the LPGA player of the year award and the only South Korean player to win the Vare Trophy twice with the lowest average score when she reached the gold medal podium at the 2016 Olympics. Inbee Park and Jiyai Shin are also the only South Korean players to have topped the world rankings. Inbee Park has won the Grand Slam championship seven times. South Korea has become the strongest country in women's golf, accounting for 21 of the world's top 50 players. [9]

\section{B. Development status of golf courses in South Korea}

1) Golf course: The Korea golf course operators association has published the 2016 Korean golf course status and customer contact. In 2015, there were 483 golf courses, 265 popular golf courses and 218 member golf courses. In 2016, there were 486 golf courses, 290 public golf courses, and 196 membership golf courses, an increase of $0.6 \%$. In $2015,35,411,923$ people visited golf courses, and in 2016, 36,726,861 people visited golf courses, an increase of 3.6 percent. In 2006 , membership golf courses were visited by $6,146,140$ people and public golf courses by $13,57,219$ people visited public golf course. In 2016, the figure is $19,663,850$ and 36,726,861 respectively. (See "Table I")

TABLE I. COMPARISON OF THE NUMBER OF GOLF COURSES IN SOUTH KOREA IN 2015 AND 2016

\begin{tabular}{|c|l|l|l|l|l|l|}
\hline \multirow{2}{*}{ Road (Province) } & \multicolumn{2}{|c|}{2016} & \multicolumn{2}{c|}{2015} & \multicolumn{2}{c|}{ Growth rate } \\
\cline { 2 - 7 } & Courses & $\begin{array}{l}\text { Number } \\
\text { of holes }\end{array}$ & Courses & $\begin{array}{l}\text { Number } \\
\text { of holes }\end{array}$ & Courses & $\begin{array}{c}\text { Number } \\
\text { of holes }\end{array}$ \\
\hline Gangwon-do & 58 & 1058 & 59 & 1067 & $-1.7 \%$ & $1.7 \%$ \\
\hline Gyeonggi-do & 158 & 3182 & 158 & 3142 & $0.0 \%$ & $1.3 \%$ \\
\hline Gyeongsangbuk-do & 49 & 899 & 48 & 890 & $2.1 \%$ & $1.0 \%$ \\
\hline Gyeongsangnam-do & 49 & 964 & 47 & 919 & $4.3 \%$ & $4.9 \%$ \\
\hline Chungcheongbuk-do & 36 & 675 & 37 & 675 & $-2.7 \%$ & $0.0 \%$ \\
\hline Chungcheongnam-do & 27 & 471 & 26 & 426 & $3.8 \%$ & $10.6 \%$ \\
\hline Jeollabuk-do & 25 & 446 & 26 & 446 & $-3.8 \%$ & $0.0 \%$ \\
\hline Jeollanam-do & 43 & 753 & 42 & 735 & $2.4 \%$ & $2.4 \%$ \\
\hline Jeju & 41 & 726 & 40 & 726 & $2.5 \%$ & $0.0 \%$ \\
\hline Total & 486 & 9201 & 483 & 9026 & $0.6 \%$ & $1.9 \%$ \\
\hline
\end{tabular}

2) Screen golf: According to statistics in 2008, there were 3,500 screen golf courses in South Korea at that time, with an average daily attendance of up to 300,000 people. The market size was estimated to reach 300,000 people and the market size was estimated to reach about 400 billion won. Screen golf courses are relatively inexpensive and are not subject to the season, so more and more people choose to go to screen golf courses. [3] There are now 4,000 screen golf courses in Seoul alone and 8,000 across the country.

\section{Golf in South Korea}

In 1998, Seoil College opened the discipline of social sports golf, which was the earliest golf-related major. In the same year, Chubu University set up a golf course. In 1999, KyungHee University set up the subject of golf management, Hoseo University set up 
the subject of golf instruction, and Yong In University set up the subject of golf. In 2000, the Golf instruction of Konkuk University was established. Pusan University of Foreign Studies, Daegu University and Taman University have successively opened golfrelated disciplines. There are also some colleges and universities that offer a two-year course in golf. Golf driving range and related golf facilities are available in colleges and universities that set up golf majors in South Korea. There are about 40 colleges and universities in Korea that have golf driving ranges. Japanese consortia and school corporations also plan to open specialized golf universities. More golf universities and related disciplines will be established in the future, and golf has become the most popular recreational sport in South Korea.

\section{Golf IN ChINA}

\section{A. The development of golf in China}

In 1984, Chung Shan Hot Spring Golf Club, the first golf course in mainland China, was founded by Henry Fok and Cheng Yu-tung. In 1985, Chung Shan Hot Spring Golf Team was established, with nine boys and nine girls formed the first golf team in China. In 1985, the Shenzhen Golf and Country Club was completed. In May 1985, with the approval of State Physical Culture and Sports Commission, China Golf Association was established in Beijing. In 1986, the "Chung Shan Cup" professional and amateur international invitational tournament was held in Chung Shan Hot Spring Golf Course, which was the first international golf tournament held in China. In 1986, Chinese golfers participated in the Seoul Asian Games for the first time. China sent four competitors to the competition, and Zheng Wengen of China finished 41st. In 1987, the first golf course in Beijing officially opened. In 1988, the first Women's Amateur Open was held at Chung Shan Hot Spring Golf Course. In 1990, the opening of the Beijing Country Golf Club was the first of its kind in China. In 1995, China held its first international events: Volvo China Tour and Volvo China Open. The tournament has expanded the influence of golf in China. In the same year, the 41st World Cup of Golf was also held. [11] In 2005, Ye Liying became the first Chinese player to participate in the LPGA. In January 2001, under the initiative of Aylwin Tai, the first National Club Managers Conference was held in Wuyi Fountain Palm Golf Club. It has been held for 14 sessions. It is an industry fair for golf. The high-level member of national golf clubs gather together to discuss the development of golf in China. In 2004, Zhang Lian-wei received the fifth wild card invitation in Augusta's 70-year history to participate in the 68th US Master Golf, the first grand slam for a mainland golfer. At the 2010 Guangzhou Asian Games, the Chinese women's golf team made a breakthrough in both the team and individual events, not only winning the first silver medal in the team event, but also gaining the silver medal in the individual event for 14-year-old Yan Jing of the Chinese team. In 2012, Feng Shanshan made a solid start at her second grand slam, the Winmans LPGA Championship, winning her first LPGA title and first grand slam title in more than four years of career change. In 2016, Feng Shanshan made another historic achievement, winning the bronze medal in Women's Golf at the Rio Olympic Games. [7]

\section{B. The status of golf courses in China}

1) Golf course in China: China still has a lot of room to improve in terms of facilities per capita. In 2015 , there were 438 golf facilities with 9,753 holes, or about 542 18-holes. The average population per hole in China is 140,185 , much higher than the global average (12,570/hole) and the Asian average (46,962/hole). With the improvement of national income and consumption level, there is still much room for development of golf in China. China, with 1.5 billion people, has only 496 golf courses. [12] (See "Fig. 1") 


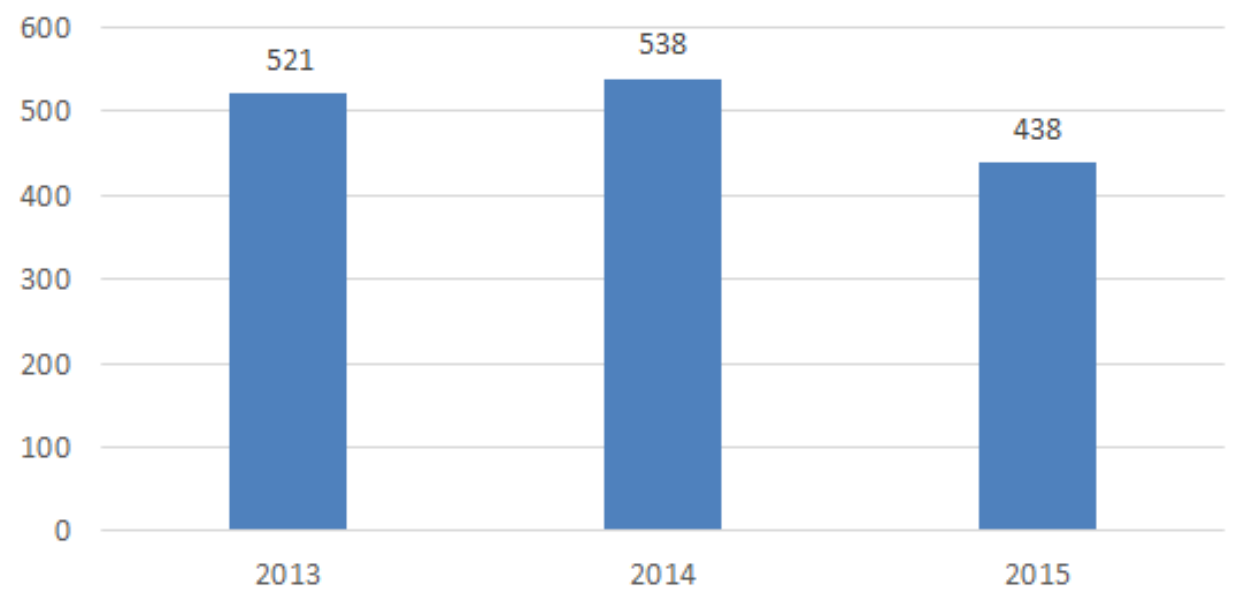

Fig. 1. The total number of golf facilities in China.

The core population of golf is nearly 400,000 , and the total number of rounds is declining. The number of golfers and rounds in China continued to grow from 2009 to 2013, reaching an all-time high in 2013 before slowly declining. China's core golf population fell 4.9 percent to 390,000 in 2015 from 410,000 in 2014 and 424,000 in 2013. The total number of rounds in 2015 was 10.02 million, down $15.8 \%$ from 11.9 million in
2014 and 12.15 million in 2013. From 2009 to 2013, the total number of golf rounds in China increased by 3.43 million, or $39.3 \%$, or $8.7 \%$ annually. [12] (See "Fig. 2")

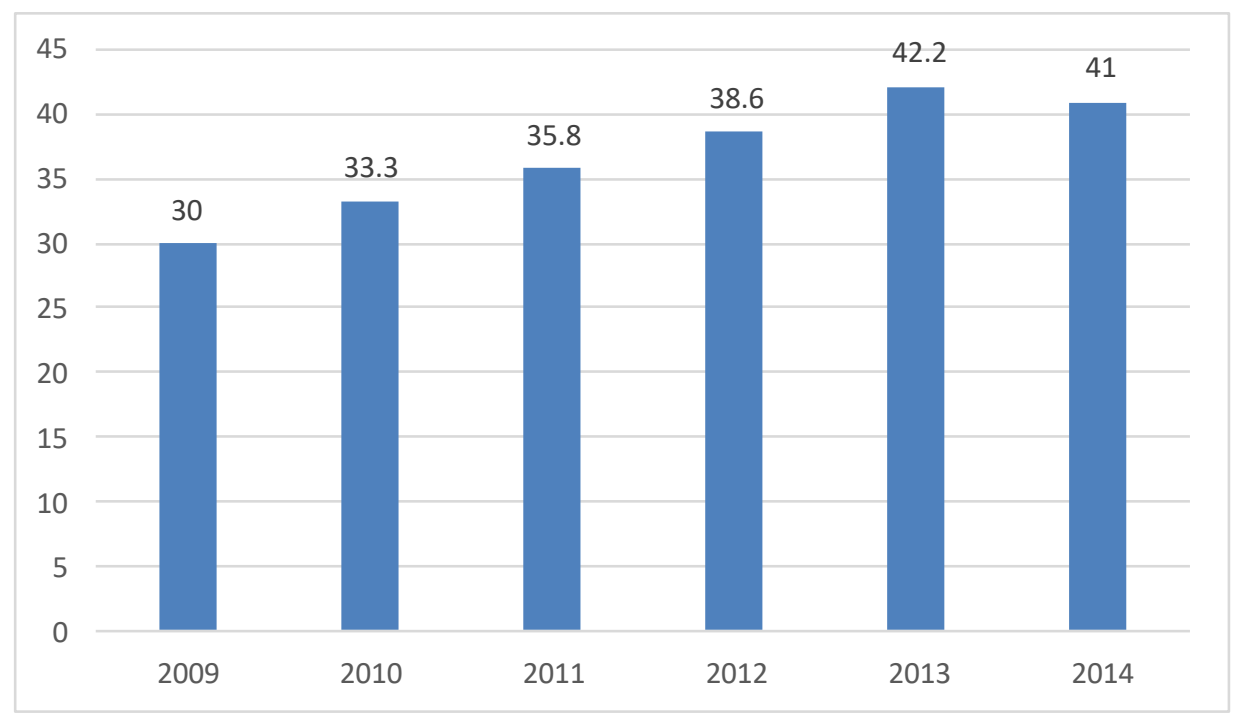

Fig. 2. Core population of golf $(10,000)$.

\section{Golf course in college}

The earliest golf professional education in China began in 1995. It is the first golf management major opened by Shenji I Higher Vocational and Technical College, but it is only a vocational education, not a real golf major. Until 1997, the establishment of Golf College of Shenzhen University prompts the development of golf professional education in China. At the beginning of the 21st century, Beijing Sport
University and Beijing Forestry University started the golf professional training activities in different fields of the golf industry. At present, golf courses are offered in China's higher physical education institutions. For example, the College of Social Sports of Capital University of Physical Education and Sports offers adult correspondence course in golf direction. Golf class is available in Guangzhou Sport University, Nanjing Institute of Physical Education and Sports, Shanghai University of Sport, Hebei Sport University, 
Shandong Sport University and Wuhan Sports University. In 2006, Capital University of Physical Education and Sports launched adult golf education under the major of social sports. In 2012, the school purchased indoor golf simulator. In 2013, the university began to recruit graduate students of golf teaching and training theory and practice. Since 2012, Tianjin University of Sport has offered golf and management under the major of social sports, with only 5 students enrolled every year. In 2012, Chengdu Sport University took golf as an optional course for students majoring in leisure sports, and provided postgraduate education in golf teaching and training theories and methods. Department of Social Sports of Xi'an Physical Education University recruited golf teachers in 2013. Jilin Sport University also set up golf education base, and team up to participate in the College League Golf Tournament. Eight schools, including Beijing Sport University, Shanghai University of Sport and Guangzhou Sport University, have set up golf classes. Unlike other sports, golf driving range requires a larger area. A survey found that half of the sports schools have their own golf driving range, including Hebei Sport University, Wuhan Sports University, Nanjing Institute of Physical Education and Sports, Shenyang Sport University, Shanghai University of Sport and Harbin Sport University. Colleges and universities are also increasing investment in golf education. In 2012, Hebei Sport University invested 6 million yuan to build a golf driving range.

\section{DEVELOPMENT PLAN FOR THE POPULARIZATION OF GOLF IN CHINA}

\section{A. Improving the utilization of the golf course}

In 2015, there were 438 golf courses in China, generating a total of 10.02 million rounds, with an average of 22,876 rounds per course. However, Korea's 483 golf courses produce a total of 35.41 million rounds annually, with an average of 73,312 rounds per course. The average number of rounds played per golf course in South Korea is three times that in China, indicating that there is still a lot of room for use in China. China can operate on bulk-cheap basis. At present, the popular golf courses in China belong to the Orient Group Incorporation. The price is low, and the club decoration is simple but can meet the basic demand of customers. The club has been operating in a low-cost, environmentally friendly way, greatly promoting the popularization of golf. A number of golf courses are already trying to cut prices. A check of the golf course booking software shows that the price of each round around Beijing is as low as 290 yuan, with half of the courses priced at around 380 yuan.

\section{B. Improving the ability of professional golf competition}

Se Ri Pak, Mi Hyun Kim, Grace Park, Hee-Won Han successively won on the American stage and became national stars. Golf in South Korea has taken off. Chinese professional golfers have made great achievements in various international events, inspiring the enthusiasm of golf from all walks of life and promoting golf to be more widely seen by the Chinese public. Cultivating more golf stars will make more people enjoy the game.

\section{Popularizing golf in sports colleges}

Dozens of universities have opened golf courses in South Korea, almost all with driving ranges. There is a big discount for school students to play on the course. At Yong In University in South Korea, for example, students can get a monthly card for just 50,000 won, or about 300 yuan. The school also offers optional golf courses, giving every student the opportunity to learn golf. Almost every teacher in the school can play golf. At the same time, the courts are also used by offcampus staff, so that not only are they fully utilized, but the school also gets some income. Although there is no golf major in China, golf courses are offered in sports colleges and universities. Half the schools have their own golf driving range. Colleges and universities are also increasing investment in golf education. In 2012, Hebei Sport University invested 6 million yuan to build a golf driving range. The construction of golf courses in universities has increased the popularity of golf among students. It is necessary to make full use of the golf course and open optional courses so that every student can have the opportunity to learn golf.

\section{Screen golf course}

South Korea has more than 7,000 screen indoor golf courses. There are only 500 in China. This system can realize the purpose of real experience, practice and teaching. Players do not have to travel long distances to courses far from the city, nor are they affected by weather factors such as rain and snow. Especially in winter when outdoor courses are not available, indoor screen golf is the best choice. Because of its low cost, small space, low operation cost, zero safety problem, and convenient upgrade, screen golf is suitable for the increasingly busy urban life. It has become the new favorite of golfers and is now widely popular all over the world.

\section{CONCLUSION}

By comparing the current situation of golf between China and South Korea, it can be seen that the average golf course played in South Korea is three times as many times as that in China, indicating that there is still a high utilization space for the existing golf courses in 
China. There are more than 7,000 screen indoor golf courses in South Korea, while there are only 500 in China, where screen golf courses still have a large market. The opening of golf majors in universities and the establishment of golf driving ranges have promoted the popularity of golf.

\section{References}

[1] Lian Youqun. Zhang Hongwu.Comparative Study of Development of Golf in China and New Zealand [J]. Wuhan: Journal of Wuhan Institute of Physical Education. 2011 (2) 3437. (in Chinese)

[2] Chen Shuai. Study on the Rooting and Development of Golf Culture in China [J]. Journal of Guangzhou Physical Education Institute. 2013 (1) 46-49. (in Chinese)

[3] Gu Yue, Qin Li. Present Situation and Development of Golf Undergraduate Education in China in Past 20 years [J]. Journal of Wuhan Institute of Physical Education. 2018: 79-85. (in Chinese)

[4] Qi Chunyan. Theoretical Research on the Evolution Path of Golf System in China. [D] Beijing: Beijing Sport University, 2013. (in Chinese)

[5] He Caihua. Discussion on the Present Situation and Sustainable Management of Golf Industry in China [D]. Chaoyang University of Technology. (in Chinese)

[6] Lee Jung-Yeon. Students of Golf Majors Satisfaction with the College of Golf and Education Environment. 2015 [D].

[7] Segmentation of Visitors at Domestic Professional Golf Tournaments-Focusing on Leisure Benefits [D]

[8] Liang Meng. "Coming-of-age Ceremony" of China golf federation annual meeting in chongqing in October. Sohu sports. July 12, 2017. (in Chinese)

[9] Wang Xiaoyi, Feng Shanshan Won the Bronze Medal of Women's Golf, Lin Xiyu hit the first a hole in one.

[10] 2008 Golf Masters Player Information-Choi Kyung-ju. Tencent sports. April 10, 2008. (in Chinese)

[11] Inbee Park. The Olympic Gold Medal was the Pinnacle of My Career to Confound the Doubters. August 21, 2016. (in Chinese)

[12] A Chronicle of Chinese Golf History http://www.sohu.com/a/129917686_638981

[13] 2016 Development Status and Market Scale of China's Golf Industry. http://www.chyxx.com/industry/201611/463150.html 